\title{
El partido Vanguardia Comunista: elementos para avanzar en una caracterización del maoísmo argentino (1965-1971)
}

\author{
The Communist Vanguard party: elements to advance a characterization of \\ Argentine Maoism (1965-1971)
}

Brenda Rupar*

\begin{abstract}
Resumen: Vanguardia Comunista fue la primera organización argentina en adoptar explícitamente el maoísmo como fundamento político ideológico. El presente trabajo busca indagar cómo fue y en función de qué adoptaron el maoísmo y cómo lo significaron y transformaron en el período abordado, en relación con su análisis y práctica en la sociedad argentina. A través del recorrido planteado y las fuentes partidarias trabajadas intentamos delinear los rasgos que fue adquiriendo el maoísmo argentino, del que Vanguardia Comunista fue uno de sus exponentes. Proponemos que, en un camino que no fue unívoco ni lineal, el maoísmo proveyó a esta organización de herramientas a través de las que pudieron repensar la realidad argentina, en diversos aspectos como la vía, el camino y el carácter de la revolución, y el significado del peronismo como corriente política.
\end{abstract}

Palabras clave: Revolución China, maoísmo, Argentina, Vanguardia Comunista

\begin{abstract}
Vanguardia Comunista was the first argentinian organization that adopted maoism as its political ideological fundaments. The aim of the present article is to focus in the process of how and why they adopted maoism and what that it meant, according to their documents and political activities. Through the particular history of this political party, we try to offer one way to analyze the characteristics of Argentinian maoism in its first years. We propose that it was not a simple, single and lineal way and that maoism finally gave them some theorical and political tools to think the argentinian society, such as the way and type of its revolution and the sense of peronismo. This study is part of a growing body of research on the impact of socialist revolutions in Latin America.
\end{abstract}

Key words: Chinese Revolution, maoism, Argentina, Vanguardia Comunista

\footnotetext{
* Argentina, Doctoranda en Historia en la Facultad de Filosofía y Letras de la Universidad de Buenos Aires (UBA), con beca Interna Doctoral del Consejo Nacional Investigaciones Científicas y Técnicas (CONICET). Mestre em História por la Universidade Federal Fluminense (UFF), Brasil. Integrante del Grupo de Estudios sobre Acumulación, Conflicto y Hegemonía (GEACH) y del Centro de Investigaciones sobre Economía y Sociedad en la Argentina Contemporánea (IESAC), ambos radicados en la Universidad Nacional de Quilmes brendarupar@yahoo.com
} 
Recibido: $13 / 02 / 2017$

Aceptado: 05/ 05/ 2017

\section{Introducción}

La influencia de la revolución y el socialismo en China impactó sobre diversas organizaciones políticas y culturales en la Argentina desde fines de los años `50 y, a partir de la década del '60, incidió también sobre corrientes del Partido Socialista y del propio peronismo.

Dentro de las variadas maneras en que la Revolución China y el maoísmo influyeron en la vida política argentina, en esta ocasión escogemos adentrarnos a la problemática a través de Vanguardia Comunista. El propósito es contribuir a abordar la génesis y características de la corriente maoísta en Argentina, contemplando la relación entre la realidad nacional de dicho país, las elaboraciones y prácticas de la organización en el período propuesto, y el maoísmo, como vertiente específica dentro del Movimiento Comunista Internacional. ${ }^{1}$

Vanguardia Comunista (VC) fue la primera organización en conformarse adoptando el bagaje político teórico que brindaba el maoísmo ${ }^{2}$. Entre sus particularidades se encuentran el hecho de que proviene del socialismo argentino (a diferencia de la mayoría de las organizaciones maoístas del mundo) pero que entre sus definiciones identitarias se reivindicará en la tradición del comunismo. Integrado inicialmente por unas pocas decenas de militantes y no llegando nunca a ubicarse entre los partidos más influyentes de la Argentina, tuvo sin embargo una notoria presencia en varios conflictos obreros de inicios de la década de 1970 y en sus filas encontramos a importantes representantes de la intelectualidad de dicho país. Definidos a crear un partido, se dedicaron los primeros años a elaborar las bases teóricas y, luego, a desarrollar su trabajo de masas. Conformado en partido político por la confluencia de varias organizaciones (de las cuales el Partido Socialista Argentino de Vanguardia aportó la mayor cantidad de personas), sus elaboraciones político teóricas irán virando entre 1963 y el inicio de la última dictadura argentina en 1976. De la postulación acerca de la necesaria guerra popular que siguiera el camino del campo a las ciudades, posteriormente defenderá el camino insurreccional en los centros urbanos. Asimismo, criticaron un inicio casi exclusivamente vinculado al trabajo

\footnotetext{
${ }^{1}$ Acerca de la influencia de la Revolución China y el maoísmo en América Latina en general, remitimos a Matthew Rothwell, Transpacific Revolutionaries: The Chinese Revolution in Latin America. New York: Routledge, 2013, Brenda Rupar. A emergência do maoísmo na Argentina: uma aproximação através de Vanguardia Comunista e o Partido Comunista Revolucionario. Dissertação de Mestrado. Niterói: UFF, 2016; Marisela Connelly "Influencia del Pensamiento de Mao en América Latina”. En: Estudios de Asia y África XVIII: 2, (1983) 215-231; Robert Alexander, International Maoism in the Developing World. London: Paeger, 1999. De todos modos, consideramos que la reconstrucción sistemática de este problema es aún una tarea pendiente.

${ }^{2}$ Junto al Partido Comunista Revolucionario (escisión del Partido Comunista), fue uno de los dos principales partidos maoístas argentinos en los años previos al Golpe de Estado de 1976.
} 
ideológico y de formación interna y clandestina y dieron lugar a la organización de un "partido de masas", que creó frentes de trabajo en el movimiento obrero, en el movimiento estudiantil y entre el campesinado y los intelectuales. ${ }^{3}$

Uno de los ejes del presente texto es analizar cómo fue y en función de qué adoptaron el maoísmo, cómo lo significaron y transformaron en esos primeros años como VC (1965-71) dando origen y forma a esa corriente en Argentina. ${ }^{4}$ A su vez, nos proponemos indagar si es posible constatar la intención de integrar "socialismo", "peronismo" y "revolución', tal como ha postulado recientemente Cristina Tortti en su caracterización de las organizaciones de la "Nueva Izquierda" en Argentina."

En este trabajo utilizaremos como fuentes los documentos fundacionales, congresos y otras publicaciones seleccionadas de la organización, y también escritos posteriores de balance sobre la época o la historia del partido. A través de dichos materiales nos proponemos reconstruir y responder cuestiones tales como qué prácticas y posiciones generan las rupturas, cuándo se constituyen como organización, qué puntos los reúnen, cómo se posicionan frente al peronismo, al guevarismo y al foquismo, qué tipo de revolución proponen, cómo y por qué se acercan al maoísmo y qué significó para ellos.

\section{Del Partido Socialista Argentino a Vanguardia Comunista}

Fundado en 1896 en crítica y oposición a la política expresada por la oligarquía terrateniente gobernante, el Partido Socialista Argentino se propuso representar los intereses de los trabajadores en pos de conseguir, en primer lugar, las mejoras en sus condiciones de vida y trabajo y, en segundo lugar, conducir a la transformación de la sociedad capitalista. Con permanentes debates y tensiones internas, el partido sufrió una serie de escisiones a lo largo de su trayectoria, siendo una de ellas la del futuro Partido Comunista Argentino en 1918.

El "fenómeno peronista" (no sólo los gobiernos, sino también el golpe posterior y la identidad de los trabajadores que permanecieron leales a pesar de las expectativas) conmocionó a la organización, cuya dirección expresaba un anti-peronismo bastante consecuente. A finales de la década de 1950, al calor de la creciente combatividad nacional e internacional, fue definiéndose un sector más de "izquierda" dentro del PSA, con un gran componente juvenil, que comenzó a disputar en línea y espacios de dirección. El triunfo de

\footnotetext{
${ }^{3}$ En enero de 1976, en el marco del 2do Congreso pasaron a llamarse PC (m-1), nombre que prácticamente no usaron debido al golpe de Estado de marzo de 1976. En 1978, la dictadura cívico militar bajo el mando de Videla lanzó un plan de exterminio sobre la organización que devino en la detención y desaparición de los principales dirigentes y muchos militantes, lo cual generó la desestructuración del partido como tal.

${ }^{4}$ En este trabajo procuramos analizar los aspectos distintivos o constitutivos del maoísmo como corriente en Argentina a través de VC. Para una descripción pormenorizada sobre dicho partido, remitimos a los trabajos de Adrián Celentano, "La formación de Vanguardia Comunista, de la crisis del socialismo a la adopción del maoísmo y el problema de la construcción del partido revolucionario entre 1965 y 1969," Ponencia presentada en las VII Jornadas de Historia Política. Tandil, 6 y 7 de setiembre de 2012 y "Maoísmo y Nueva Izquierda. La formación de Vanguardia Comunista y el problema de la construcción del partido revolucionario entre 1965 y 1969”, La Nueva Izquierda Argentina (1955-1976). Socialismo, peronismo y revolución. Rosario: Prohistoria, 2015. 83-109.

${ }^{5}$ María Cristina Tortti, (org) La Nueva Izquierda Argentina (1955-1976). Socialismo, peronismo y revolución. Rosario: Prohistoria, 2015 15-33
} 
la Revolución Cubana en 1959 atizó la situación, y los debates sobre su interpretación y alcances se sumaron a los ya existentes acerca del peronismo y el tratamiento a éste: si para unos la clave residía en fortalecer la propia organización y desde allí disputar a los trabajadores peronistas (con diferencias entre los que sostenían que eso sería centralmente a través del partido y aquellos que opinaban que sería a través de frentes amplios integrados y motorizados por ellos), por el contrario para un sector fuertemente representado por la Juventud y el ala más de "izquierda" la clave residía en la unidad con el peronismo. ${ }^{6}$ Dichas cuestiones eclosionaron en torno a las elecciones de 1960 y nuevamente en 1961, deviniendo en una nueva ruptura partidaria. El sector radicalizado se constituiría como Partido Socialista Argentino de Vanguardia.

A partir de ese nuevo armado, que se definía como "socialista, Latinoamericanista y Fidelista", el PSAV puso en marcha la política de Frente que le había sido impedida dentro del PSA. Entendiendo a la Revolución Cubana como una "Revolución Nacional", fueron virando hasta teorizar sobre el Frente Nacional que debían armar con centro en los trabajadores, pero dando lugar a determinados sectores de la burguesía, pensando fundamentalmente en el peronismo. Confiando en quebrar la identidad clase obrera/peronismo, buscaban una política que les permitiera disputarla.

Otro elemento importante de las definiciones tomadas por este grupo, lo constituye el haberse proclamado, al mismo tiempo, un partido marxista-leninista, tradición que les era ajena y que los convertiría en contendientes del Partido Comunista con el cual habían tenido cierto acercamiento antes de la constitución del PSAV ${ }^{7}$. A su vez, los llevaba a un tipo de organización (celular, con un sistema de funcionamiento centralista-democrático) que no era propio del PSA. Recién constituidos, debían decidir qué harían frente al llamado para elecciones provinciales ese año y el siguiente. Con un peronismo que ya habilitado a presentarse analizaba la conformación de listas propias, los socialistas de vanguardia ponían el foco en qué táctica darse: si armar listas mixtas con candidatos de las diferentes tendencias o bien llamar a votar a los peronistas, que es lo que terminó sucediendo en las elecciones de Santa Fe y nuevamente en las de Buenos Aires en 1962, en donde además coordinaron la propaganda.

La anulación de las elecciones y la aceptación pasiva del peronismo, se daba a la par de que el estrechamiento de los vínculos con Cuba convencía a una parte acerca de la necesidad del foco rural y la guerrilla. La tensión, ahora entre estos conflictos, se reeditaba en nuevas condiciones. Será una versión doble del periódico No Transar $\mathrm{N}^{\circ} 15$ el que testimonie una nueva fractura. Hacia finales de 1963 y 1964, una veintena de militantes emprendió el camino de construcción de una nueva organización que en abril de 1965 adoptó el nombre de Vanguardia Comunista y que tuvo por principales referentes a Elías Semán, Rubén Kritskautsky y Roberto Cristina.

\footnotetext{
${ }^{6}$ Para profundizar sobre el tema, remitimos al capítulo III “Los dilemas del PSA, 1959-1960”, en María Cristina Tortti, El "viejo" partido socialista y los orígenes de la "nueva" izquierda, Buenos Aires: Prometeo, 2009

${ }^{7}$ Juntos editaron la revista "Che". M Cristina Tortti,, "La nueva izquierda a principios de los '60. Socialistas y comunistas en la Revista 'Che'”, Revista Estudios Sociales No 22/23, (2002) 145-162.
} 


\section{Vanguardia Comunista y la búsqueda de una identidad}

El viejo PSAV constituyó el intento de conciliar el marxismo-leninismo con el populismo. La dirección (...), resolvió la contradicción a partir de la crisis partidaria, renunciando al marxismo-leninismo. (...) Hace un año el PSAV (...) incurrió en el seguidismo abierto del peronismo ${ }^{8}$.

Esta reflexión de Elías Semán expresa los límites que rápidamente encontró el PSAV al haberse conformado fundamentalmente en torno a la oposición a la dirección anterior. La tensión entre quienes impulsaban una organización independiente inscripta en el marxismoleninismo y los que ponían por delante acercarse al peronismo, eclosionó luego de las elecciones de 1962 cuando el PSAV decidió levantar sus candidaturas y llamó a apoyar la lista del peronismo en las elecciones de Buenos Aires. La vieja preocupación por "virar" a la clase obrera y disputarle la dirección al peronismo, había sido trastocada por el denominado "seguidismo" de aquéllos.

Como ya mencionamos, unos pocos militantes emprendieron el camino de crear una nueva organización. En escritos posteriores consideraron que, “inicialmente [eran] un círculo de propaganda de ideas revolucionarias, integrado mayoritariamente por estudiantes y profesionales “9 . Esto no constituía una excepción, sino que fue una de las expresiones del proceso de radicalización que involucró a las capas medias en todo el mundo. Desde abril de 1964 la dirección del periódico No Transar estaba bajo la responsabilidad de Elías Semán, lo que dotaba a la incipiente organización de un elemento tanto de difusión hacia el exterior, como organizativo al interior ${ }^{10}$. A la par, la escritura y publicación de algunos materiales, fueron cohesionando a los militantes en torno a definiciones teórico-políticoideológicas que implicaban la doble operación de confrontación e identidad con otras corrientes. Los tres primeros escritos que guiaron ese proceso fueron "Derrotemos al Revisionismo", "El Partido Marxista Leninista y el Guerrillerismo" y "Denunciamos el falso comunismo de Codovilla" (recopilación de artículos), todos ellos escritos entre 1964 y 1965.

En general, son todos trabajos con una fuerte carga teórica, de definiciones conceptuales y político ideológicas, aunque se precaven de señalar que "no es un ensayo de marxismo académico, [sino] la herramienta militante de un grupo de revolucionarios"11. Asimismo, una primera lectura de los títulos y su contenido, revela un diálogo con experiencias y ensayos revolucionarios de dentro y fuera de la Argentina.

En este momento en el que surgen y siendo que se proponen convertirse en un partido revolucionario, hay varias cuestiones sobre las que deben pronunciarse: cómo debe ser la revolución en dicho país, por qué vía pretenden alcanzar el poder y, vinculado a esos

\footnotetext{
${ }^{8}$ Elías Semán, El Partido Marxista Leninista y el guerrillerismo, Ed No Transar, 1964. Usamos versión editada por El Topo Blindado. Buenos Aires, 2013. 51

${ }^{9}$ Américo Soto, Vidas y Luchas de Vanguardia Comunista, Tomo I, Buenos Aires:Nuevos Tiempos, 2004; 40 y VC, Cuadernos Rojos, $\mathrm{N}^{\circ}$ 2, [CC de Vanguardia Comunista] Mimeo, setiembre 1970, 11

${ }^{10}$ En la tradición marxista-leninista, el periódico partidario cumple esa función, según había proclamado Lenin en su obra, ¿Qué Hacer?”, de 1902.

${ }^{11}$ AAVV, Derrotemos al Revisionismo, Bs As:Ed. No Transar, 1964, 4
} 
temas, qué análisis hacen del peronismo y qué táctica se iban a dar hacia ello, qué toman y qué critican de la Revolución Cubana y de otras experiencias revolucionarias. Contemplando conjuntamente varias de estas cuestiones, otro elemento definitorio será el de los posicionamientos frente al debate dentro del Movimiento Comunista Internacional ${ }^{12}$. Estos temas aparecen recurrentemente en los escritos mencionados, por más de que individualmente se concentren en alguno(s).

Para comenzar, "Derrotemos al revisionismo"13 tiene las características comunes a los textos elaborados por una organización luego de una ruptura. En este caso, Elías Semán destina una de las siete páginas del documento a justificar la ruptura con el PSAV, que según indicaba, confiaba en que "algún sector interno del peronismo "cortara las cabezas de los dirigentes vendidos" [entrecomillado en el original]" y adhería a cierto espontaneísmo por el cual la clase obrera "superara la ideología del movimiento". Continúa diciendo que fue en ese proceso de ruptura y distanciamiento que se aproximaron al "bagaje teóricopráctico del marxismo, negado por (...) el viejo PSAV", lo que los habría llevado a una reconsideración general de lo que luego entendieron que eran los errores fundamentales de dicho partido: "el desprecio objetivo por la ideología y por el papel del partido de la clase obrera". De allí devendrían los demás errores, denominados "desviaciones". Resueltos a elaborar una estrategia revolucionaria que "reagrupara a los militantes marxistasleninistas", denunciaron la "imposibilidad" del PCA para cumplir el rol de vanguardia.

A partir de allí comienza una segunda parte del documento, caracterizado por la justificación de dicha afirmación, que se remonta estrictamente a la política internacional de la época y el MCI. Desde allí criticaban el "revisionismo contemporáneo" al que adscribiría el PCA y se colocaban a sí mismos bajo la guía del Partido Comunista Chino, que a la par de denunciar el revisionismo, les garantizaría hacerlo desde una "justa posición revolucionaria".

El texto continúa con una síntesis de los elementos y momentos del desarrollo del marxismo como herramienta político-teórica (el rol del proletariado, la necesidad del partido, El Estado, el Imperialismo, los revisionistas), tomando y seleccionando sobre todo en la segunda mitad del siglo XX aquéllos que irían a ser su justificación. ${ }^{14}$

En este primer momento, el optar por el lado chino en la contienda, los posiciona a favor de determinados elementos que estaban en debate: en contra de la coexistencia pacífica, que no sería más que el acatamiento de una política de los Estados Unidos "para preservar la vida del imperialismo corrompiendo los Estados Socialistas, y frenando a lucha de los pueblos oprimidos y de la clase trabajadora" y a favor de la vía "revolucionaria" para

\footnotetext{
12 Desde el XX Congreso del PCUS en 1956, se abrieron debates y posiciones enfrentadas en tono a la coexistencia pacífica, la vía para la revolución y el tipo de Estado en el socialismo, que culminaron en la ruptura de relaciones entre el Partido Comunista de la Unión Soviética y el Partido Comunista Chino en 1963. Como consecuencia de todas esas acusaciones, el PCCh acabó acusando al PCUS de revisionista del marxismo-leninismo y este, a su vez, acusaba a los chinos de izquierdistas y nacionalistas. Dicho proceso, conocido como debate chino-soviético atravesó a las organizaciones de izquierda de todo el mundo. PCUS, "Por el triunfo del marxismo - leninismo creador. Contra la revisión del rumbo del Movimiento Comunista Mundial", revista Kornmunist no 11, 1963 (versión de la Agencia de Prensa "Novosti"-Uruguay); PCCh, Polémica acerca de la línea general del Movimiento Comunista Internacional, Pekín: Ediciones Lenguas Extranjeras, 1965.

${ }^{13}$ AAVV, Derrotemos...

${ }^{14}$ Aquellos que usaban para criticar el papel de la URSS y sus posiciones a partir del XX Congreso.
} 
la toma del poder, entendiendo que ésta sólo podía ser armada y "no pacífica". Y argumentaban sobre estos puntos acusando a la URSS de "leninistas de palabra y servidores del imperialismo en los hechos", en sintonía con la caracterización realizada por Mao sobre la restauración en el bloque soviético.

Asimismo, inscribiéndose en la tradición del marxismo-leninismo, declaraban la necesidad de conformar un partido político que unificase a todos los marxistas-leninistas argentinos, independientemente de donde se encontrasen militando en dicho momento. Ello retoma el inicio del documento y la disputa por militantes del PCA. La Revolución Cubana y sus posibles lecturas y conclusiones, influyeron en el curso de la política continental. Si bien en el documento recién tratado aparecía un primer indicio de debates con otras corrientes, será en "El Partido Marxista-Leninista y el guerrillerismo"15 en donde Semán se abocaría al análisis y debate de los grupos que, posicionándose a favor de la lucha armada para tomar el poder, optaban por el camino de la guerrilla y, cada vez más, al foquismo.

El primer elemento de polémica, que nos anticipa una gran contraposición entre dos elementos, será el título escogido. Puesto que, si bien se usa el nexo "y”, rápidamente el lector identifica que el autor las trata como opciones excluyentes ( $y$, a la segunda, equivocada). En el contexto de crisis del MCI y de críticas (desde varias vertientes) a la URSS, se multiplicaron las interpretaciones sobre qué y cómo debía hacerse. El denominado "guerrillerismo", apoyado en el triunfo de varias revoluciones que habían contado con guerrillas y Ejércitos de Liberación, era identificado por el autor como una de las oposiciones al "revisionismo", aunque pecaba él mismo de severas limitaciones, que lo terminaron llevando al "ultra izquierdismo". Porque según anticipaba, "la negación de los caminos incorrectos es un momento en la afirmación del camino justo"16. Diría que dos de los fundamentos de la tesis guerrilleristas eran los que nucleaban al conjunto de las equivocaciones: la concepción del campesinado y acerca del partido.

Con respecto a lo primero, señalaba que incurrían en "la sustitución del proletariado por el campesinado al frente del proceso revolucionario”. Semán, ubicándose fuertemente en la tradición marxista, anticipaba que dado que el campesinado "no es capaz de iniciar y conducir esta guerra, condena de antemano a la derrota" 17 . Criticaba asimismo que el guerrillerismo sobredimensionaría el rol y número de dicha clase ${ }^{18}$, basándose a veces en la "tesis de un país continental", tomando América Latina de conjunto y obviando ciertas especificidades nacionales y otras veces, en la fragmentación regional del país, evitando un análisis de conjunto que diese cuenta de la unificación bajo el mando estatal y la necesidad de una "estrategia única"19.

En segundo lugar, estaba la "sustitución del partido (...) por el destacamento guerrillero". En un tono irónico, criticaba que un grupo de jóvenes "organizados en un destacamento totalmente desvinculados de la clase obrera y demás clases explotadas" pretendan convertirse en "vanguardia". Si la preocupación residía en la vinculación entre

\footnotetext{
${ }^{15}$ Semán, Op. Cit.

16 Ibid., 61.

${ }^{17}$ Ibid., 62

${ }^{18}$ Más adelante, también dirá que la confunde con el semi-proletariado rural. Ibid., 74

${ }^{19}$ Ibid., $67-68$
} 
las condiciones objetivas y las subjetivas y luego, entre los elementos espontáneos y los conscientes en la lucha, entonces señalaba que justamente esto último "constituye la esencia de la concepción leninista del Partido" 20 . Y redoblaba sus críticas, acusándolos de ser "aventureros" y de poner una cuestión de índole técnica y militar al mando del contenido y la forma de la lucha de clases $^{21}$, además de acusarlos de haber hecho una lectura errada y sesgada de las revoluciones victoriosas de China, Cuba y Argelia.

El documento concluye con lo que entendemos que es el desarrollo de aquélla idea antes mencionada por Semán, de que hay que combatir líneas erróneas desde las justas y revolucionarias. Además, incluye una breve caracterización de la Formación Económica y Social (FES) argentina y de las clases que conformarían el Frente Revolucionario. Ello dialogaba con la tradición no sólo marxista-leninista, sino también con la maoísta, al buscar la integración entre el marxismo y las condiciones concretas ${ }^{22}$. En este caso, Argentina era visto como un país "capitalista dependiente del capital financiero internacional y, fundamentalmente, del imperialismo yanqui", con un "proletariado numeroso" y una alta densidad en las zonas urbanas que "alcanza a casi el setenta por ciento de la población total". En virtud de ello, la clase obrera sería la "columna vertebral" y la pequeña burguesía, el proletariado rural y, el campesino sin tierras, "clases y sectores de clases, cuya participación en el frente único de los explotados se subordinan a la hegemonía del proletariado industrial" 23 .

Una consecuencia de dicha FES sería que "la lucha contra el imperialismo" adquiría "un contenido predominantemente socialista". Ya no se trataba de una primera etapa de la revolución democrático-burguesa que desarrollara las bases materiales y democráticas sobre las cuales pasar a la etapa socialista, sino que se le asignaba dicho contenido al inicio, sin negar el carácter antiimperialista de la revolución ${ }^{24}$.

"Denunciamos el falso comunismo de Codovilla", el último publicado de estos tres iniciales $^{25}$, consiste en una compilación de nueve artículos publicados en No Transar entre mayo de 1964 y mayo de 1965. Era el que analizaba de forma más contundente la realidad argentina y se remontaba temporalmente a años previos; sin embargo, en tanto compilación de artículos que sólo fueron publicados en 1965, los anteriores (de octubre y diciembre de 1964 respectivamente) fueron debatidos y circulados con anterioridad.

La selección y el orden de los nueve artículos ${ }^{26}$ trazaban un camino argumentativo que decantaba en la necesidad y justificación de la creación de VC. De hecho, su

\footnotetext{
20 Ibid., 77

${ }^{21}$ Ibid., 80.

${ }^{22}$ Se preocuparon por diferenciar “aplicación y “integración”, tratándolas como contrapuestas.

${ }^{23}$ Ibid., 65-66

${ }^{24}$ Explicitamos esto porque, a diferencia del trotskismo, no adoptaron la revolución socialista de inicio. Si bien no se profundiza ni desarrolla esta idea, aparece un análisis sobre la Revolución Cubana en la cual la primera etapa habría estado liderada por la pequeña burguesía. Ibid. 85

${ }^{25}$ AAVV, Partido Vanguardia Comunista, Denunciamos el falso comunismo de Codovilla, Bs As: Ed. No Transar, 1965

${ }^{26}$ Los artículos son: "La epidemia del revisionismo", 15 de mayo de 1964; "A la cola del movimiento obrero", 10 de julio de 1964; "La derrota de Kruschev y el éxito de la bomba China", 6 de noviembre de 1964; "Represión, proscripción y traición", 23 de diciembre de 1964; "Por la reconstitución del Partido de los comunistas argentinos", 15 de janeiro de 1965; "Sobre la reconstitución del Partido de los comunistas", 5 de marzo de 1965; "Adoptamos el nombre de Vanguardia Comunista en la tarea de reconstituir el Partido de los comunistas", 5 de abril de 1965; "Vanguardia Comunista
} 
publicación se produjo una vez decidida la conformación de la nueva organización. Su función, junto con los dos anteriores, era contribuir a consolidar "esta etapa de la reconstitución del partido de los comunistas", que estaría dado por concentrar las fuerzas "en el frente ideológico", entendiendo que el mismo se libraba en dos campos: "desenmascarar al revisionismo" (en lo local, pero como expresión de una crisis en el MCI) y "forjar la unidad de los marxistas-leninistas" en torno a un partido que aspirase a constituirse "la vanguardia del proletariado argentino". ${ }^{27}$

Podemos afirmar que esta primera etapa de elaboraciones concluye con una serie de definiciones y tareas que orientarán a la nueva organización: la primera de ellas es la opción por la vía armada para tomar el poder, pero descartando el denominado "guerrillerismo"; la segunda es la teorización sobre la degeneración del PCA y la inexistencia de un partido comunista de vanguardia en la Argentina, por lo cual debían conformarlo; inscribiendo esa situación en un contexto general del MCI, otra definición es la toma de posición a favor del PCCh, adoptando varias de sus premisas y concepción del mundo de ese momento y de la revolución; finalmente, en dicho momento de desarrollo, debían concentrarse en la formación político-ideológica.

\section{La construcción del partido y la búsqueda de un camino para la revolución argentina}

En abril de 1965, el grupo decidió llamarse Vanguardia Comunista, lo que quedó debidamente indicado en el $\mathrm{N}^{\circ} 42$ del periódico No Transar, que desde entonces se convirtió en el "órgano de difusión de Vanguardia Comunista". Elías Semán, además de continuar siendo su director, fue su primer Secretario General. El número de militantes para ese momento fue estimado por Adrián Celentano en unos doscientos. ${ }^{28}$

Con respecto al nombre, los términos habrían estado cuidadosamente seleccionados. El primero, correspondería al "objetivo estratégico de organizar a la vanguardia del proletariado". Aunque indican que dada la situación existente, en donde el partido "no es aún una organización nacional y cuando todavía no ha echado sus raíces en la clase obrera argentina, podemos decir que el objetivo de la vanguardia marxista-leninista está en la vanguardia misma" 29 . Con respecto al segundo, se debía a que "reivindicamos la historia del movimiento comunista internacional, su ideología y su práctica". ${ }^{30}$ De esta síntesis, entonces, provendría el nombre.

Ese año viajó a China la primera delegación oficial, estrechando los lazos con aquél país $^{31}$. El PCCh reconoció, a partir de allí, a VC como interlocutor válido en Argentina. En

desenmascara el informe revisionista de Codovilla", 26 de abril de 1965 y "El informe de Orestes Ghioldi y los zig-zags del revisionismo", 14 de mayo de 1965.

${ }^{27}$ Prólogo del Documento, escrito en junio de 1965

${ }^{28}$ Celentano, "La formación...".

29 “Adoptamos el nombre de Vanguardia Comunista en la tarea de reconstituir el Partido de los comunistas", 5 de abril de 1965 en AAVV, Denunciamos ..., 33

${ }^{30}$ AAVV, Denunciamos..., 35

${ }^{31}$ Es menester señalar que existen divergencias sobre la fecha del primer viaje: Celentano en "La formación..." sostiene que fue en 1965 y Sergio Ortiz (Partido de la Liberación, Breve historia del Partido de la Liberación, documento aprobado 
ese año se difundió el discurso de Lin Piao ${ }^{32}$, "Viva el triunfo de la Guerra Popular", en el que generalizaba el camino recorrido por China (del campo a la ciudad a través de la GPP), como el indicado para todos los países oprimidos. Desconocemos la posibilidad de corroborar cuánto afectó a dicha delegación, pero lo cierto es que desde entonces se adoptó la tesis de que la revolución en Argentina sería del campo a las ciudades. Al mismo tiempo y a través de "unificarse en la lucha contra el revisionismo" establecieron vínculos con organizaciones maoístas de Chile, Colombia, Brasil, Ecuador y Bolivia. Algunas, con una fuerte línea militarista.

El naciente VC, entre las ideas e influencias que venía desarrollando, las prácticas que llevaban a cabo y las impresiones que trajeron de China, formuló una serie de premisas que orientaron esos inicios: la reafirmación de la vía armada para tomar el poder; la necesidad de impulsar la creación de un Frente único de todas las clases y sectores sociales interesados en la revolución; y a partir de ahora se sostendría la necesidad de organizar la Guerra Popular Prolongada. Todo ello debía estar bajo la dirección del Partido.

Eso se tradujo en el envío de militantes a Jujuy, Chaco, Córdoba y Tucumán. También ya tenían regionales en Mendoza, Santa Fe y Capital Federal ${ }^{33}$. Esa orientación supuso, en cierto modo, un viraje con respecto a lo que venían delineando sobre el rol del proletariado industrial y su centralidad en la FES y la revolución argentina.

A poco de emprender este trabajo, en junio de 1966 se produjo el golpe de Estado de Juan Carlos Onganía, al que caracterizaron de "proyanqui". La organización caracteriza que en dicho proceso se habría consolidado el dominio del imperialismo norteamericano, asignándole a la Argentina la condición de "neocolonia".

A pesar de la combatividad en los años previos que los había llevado a la decisión de organizar VC, ahora entendían que se producía un reflujo de las masas, debido a la colaboración de los dirigentes sindicales y algunos políticos, entre los que situaba a los del PCA. ${ }^{34}$ Desde su prensa, apoyaron a los obreros tucumanos contra el cierre de los ingenios, condenaron la noche de los bastones largos y se opusieron a toda y cuanta medida anunciaba el gobierno. En un contexto de proscripciones y persecuciones políticas, sumado al eje puesto en la construcción interna, VC privilegió cierta clandestinidad y compartimentación en su trabajo. A la par, difundían copiosamente noticias sobre China y el pensamiento de Mao-Tse-Tung, presentado como la tercera fase del marxismoleninismo.

Evidentemente con grandes debates al interior de la organización sobre algunas definiciones y el tipo de construcción que estaban realizando, una segunda delegación viajó a China en 1968. Al regreso, emprendieron la "Primera Campaña de rectificación", destinado a criticar y corregir "una desviación izquierdista, militarista y pequeño-burguesa" que en "esencia" calificaban como "derechista" puesto que se empeñaba "en encajar la

por el Comité Central del Partido de la Liberación en su XVII reunión plenaria, 8 y 9 de julio de 1995), indica que fue recién 1968. Por algunos otros datos, en este trabajo adoptaremos hasta confirmación o rectificación, que hubo uno en 1965 y otro en 1968.

32 Desde 1959, era el Ministro de Defensa, Vice-presidente ejecutivo de la Comisión Militar y miembro del Comité Permanente del Buró Político del PCCh.

${ }^{33}$ Sin embargo, en algunas no hubo trabajo significativo hasta después de 1969.

${ }^{34}$ No Transar [periódico de VC]. № 66, octubre de 1966 
realidad de nuestro país y de su revolución en la realidad de la revolución china" que los había llevado a concentrar la actividad en la preparación de la guerra. ${ }^{35}$ Según lo señalado por ex militantes en un documento de 1995, las conversaciones sostenidas con el PCCh pusieron de manifiesto el problema de la dirección del movimiento obrero y autocriticaron una línea de "aventurerismo" que de hecho vendrían practicando y que se contradecía con el rol del proletariado y el protagonismo de las masas en la Revolución de Nueva Democracia $^{36}$. La situación, además de explicarla por la poca trayectoria de la organización y su desconocimiento de la realidad argentina, también se habría visto favorecida por el "reflujo" en el conflicto político, situación que habría cambiado en 1968. ${ }^{37}$

Resolviendo el debate a favor de crear un partido de masas con base en el proletariado, Jorge Weisz viajó a Jujuy para trabajar como electricista en el Ingenio Ledesma, Rubén Kristkausky se radicó primero en Tucumán y luego en Córdoba y Elías Semán fue a Rosario, con el objetivo de seguir el proceso en el frigorífico norteamericano Swift. Producto del trabajo en los distintos frentes, la organización contaba hacia 1968 con unos cuatrocientos militantes activos, según estimaciones de Adrián Celentano. ${ }^{38}$

A inicios de 1969 circuló el documento preparatorio del I Congreso, titulado "Proyecto de Resolución sobre construcción del Partido. Vanguardia Comunista en marcha hacia la constitución del Partido Comunista Revolucionario"39. El texto está dividido en cinco partes o capítulos numerados y titulados. Básicamente los temas giran en torno a la necesidad histórica de la creación del partido, los fundamentos políticos e ideológicos, y una cantidad de definiciones iniciales sobre dicho armado. Se sintetizan allí tanto las ideas que ya constituían el corazón de la organización y que ya habían sido publicadas, como los últimos cambios que habían hecho. En él aún puede leerse cierta tensión entre dichas definiciones. Por ejemplo, se lee que la tarea era "preparar e iniciar la guerra popular que se desarrollará desde el campo para rodear y finalmente tomar las ciudades" 40 , tema sobre el que volverán varias veces en el documento, manifestando una fuerte orientación política. En ese sentido pero buscando una integración con las nuevas definiciones, afirman que "el crecimiento del partido en el proletariado industrial va posibilitando el envío de cada vez más importantes contingentes de cuadros proletarios para desarrollar el trabajo revolucionario entre los campesinos". ${ }^{41}$

Encontramos una tensión entre la definición del trabajo con centro en el proletariado y el camino revolucionario del campo a la ciudad. La misma fue abordada al señalar que

\footnotetext{
35 "Resolución del CC de Vanguardia Comunista", Cuadernos Rojos N², (septiembre 1970) 13. Ver también, No Transar [periódico de $\mathrm{VC}$ ] $\mathrm{N}^{\circ}$ 69, 1 de julio de 1968

${ }^{36}$ Ver Ortiz. Breve...El PL es uno de los que se reivindica continuador de VC en la actualidad. Las autocríticas también fueron publicadas en "Resolución", Cuadernos Rojos N2 (septiembre 1970) 13 y No Transar [periódico de VC] N 69, 1 de julio de 1968.

${ }^{37}$ No Transar [periódico de VC] $\mathrm{N}^{\circ}$ 69, 1 de julio de 1968.

${ }^{38}$ Celentano, "Maoísmo ..." 97

${ }^{39}$ Ese era el nombre que pensaban usar, pero otro partido surgido del PCA lo utilizó con anterioridad. En No Transar [periódico de $\mathrm{VC}$ ] $\mathrm{N}^{\circ}$ 89, 18/1/69 publicaron: "El CC resolvió dejar de utilizar la expresión "en marcha hacia la construcción del Partido Comunista Revolucionario" para evitar la confusión con otra fuerza política"

40 Vanguardia Comunista, Proyecto de Resolución sobre construcción del Partido. Vanguardia Comunista en marcha hacia la constitución del Partido Comunista Revolucionario, (1969) 5.

${ }^{41}$ Vanguardia Comunista, Proyecto de...,21
} 
dentro del proletariado se relacionarían con el trabajador rural, aunque el grupo principal de la clase obrera argentina se hallaba para ese entonces en las grandes ciudades (en las cuales ellos ya habían enviado dirigentes). Sin embargo, no dejaban de intentar la integración. Por ejemplo, "se adhirió a la teoría de la "Guerra Popular Prolongada", pero "privilegiando aquellas que tuvieran población de obreros rurales que laboraban en los cultivos de caña de azúcar, la madera, tabaco, yerba mate, arroz, té, vid, etc" 42 .

Con el privilegio de conocer el desarrollo casi inmediatamente posterior de los hechos, llama la atención en el documento la valoración que hace la organización sobre el estado de ánimo y la situación de las luchas. Puede hasta leerse como un cierto atraso de una realidad política que se impuso virulentamente a partir de mayo de $1969 .{ }^{43} \mathrm{El}$ Cordobazo desconcertó a la organización que, a pesar de participar activamente en las jornadas, no pudo (aunque claro, tampoco hubiese podido) incidir en el curso de los hechos. En ese contexto, VC decidió posponer la realización de su Primer Congreso, que finalmente tuvo lugar en 1971.

Comenzaron allí la "Segunda Campaña de Rectificación", a la par de que la Dirección Nacional se convertía en Comité Central. El eje de la campaña estuvo en la lucha contra concepciones "espontaneístas" que predominarían en la organización. Desde julio de 1970 se incorporó al conjunto de materiales editados, el de "Cuadernos Rojos", destinada a abordar debates teóricos y difundir resoluciones del Comité Central. En el $\mathrm{N}^{\circ} 2$ publican una resolución del $\mathrm{CC}$ en la cual además de realizar un balance del partido hasta el momento, critican algunas definiciones sostenidas y defendidas hasta el momento.

En el balance realizado en 1970, un VC aún conmovido por los sucesos y su inadecuación con lo que veían planteando como fuerza política, acreditaba que sus errores se debían a que habían forzado las características de la Revolución en Argentina intentando imitar el ejemplo Chino, lo que los llevó a hacer una mala caracterización del país y del camino revolucionario, perdiendo tiempo más que importante ${ }^{44}$. El "espontaneísmo" que diagnosticaban se expresaría no sólo en el análisis inmediatamente posterior al Cordobazo, sino también en el tipo de prácticas que desarrollaban. A partir de allí, definieron que la construcción y organización de partido y su inserción en los movimientos de masas, era clave para que la clase obrera diera un salto revolucionario. ${ }^{45}$

\footnotetext{
${ }^{42}$ Soto, Op. Cit., 29

${ }^{43}$ El Cordobazo representó un salto cualitativo con respecto a las formas de lucha y un punto de inflexión respecto del enfrentamiento a la dictadura de la autodenominada "Revolución Argentina" (1966-1973). Pero también hizo emerger tensiones ya presentes en el campo político del país, lo que llamativamente no aparece en el documento citado.

${ }^{44}$ VC, Cuadernos Rojos, 7-21

45 En 1970 el Comité Central resolvió trasladarse a Córdoba para seguir personalmente el curso de los hechos en la provincia que marcaba el pulso de la política nacional. Según el análisis de la organización, el "viborazo" de 1971 representaba un salto cualitativo en la lucha obrera, lo cual era identificado con el trabajo de la izquierda revolucionaria (en la cual se ubicaban) en su seno. Para ese entonces, VC había ganado mayor visibilidad y relevancia a partir de tener presencia en la dirección del conflicto en la planta de FIAT-Concord, que lo proyectaba nacionalmente en el campo de las fuerzas de izquierda y populares .Para profundizar sobre a experiencia de SITRAC (Sindicato de Trabajadores Concord), remitimos a Natalia Duval, Los sindicatos clasistas SITRAC (1970-1971)( Buenos Aires: CEAL, 1988 , Gregorio Flores, Sitrac-Sitram, del Cordobazo al Clasismo, Buenos Aires: Magenta, 1994 , Mónica Gordillo. Córdoba en los 60: la experiencia del sindicalismo combativo Córdoba: Colección de Manuales de Cátedra, 1996.
} 
Finalmente, en 1971 se realizó el pospuesto congreso. En él, fruto de los últimos acontecimientos de la lucha política argentina, recobraba centralidad el rol del proletariado para la revolución, lo que no dejaba de expresarse en tensión con la insistencia en la necesidad de impulsar la GPP. Esos años de proscripción, persecución y auge de lucha fueron haciendo confluir a un amplio arco opositor a la dictadura que ponía en segundo lugar la línea divisoria entre peronistas y antiperonistas. Las elecciones de 1973 inauguraron otro momento en el país y, consecuentemente, en la organización.

\section{VC y la integración del maoísmo a la realidad argentina}

Entendemos que el recorrido y las formulaciones que realizaron (y sus cambios), estaban a la búsqueda de respuestas que atravesaban a la vida política argentina y, más aún, de un partido revolucionario: sobre el tipo de país y la vía y el camino de la revolución, sobre el frente revolucionario, acerca de la burguesía nacional y el peronismo. Al mismo tiempo, reeditaban problemas clásicos de las organizaciones de izquierda: la relación entre lo nacional y lo internacional, entre el campo y la ciudad, entre vía pacífica y vía armada, acerca del Partido, sobre la conciencia de clase, sobre los países del Tercer Mundo, etc.

Creemos que ciertos elementos de VC nos permiten pensar algunas cuestiones vinculadas a la corriente maoista argentina más en general.

Un elemento central en sus posiciones iniciales, fue aquélla definición acerca de la inevitabilidad de la vía armada para la toma del poder. En 1964, denunciaban que no podían sostenerse las dos vías como igualmente válidas.

No es posible sostener la concepción leninista del Estado y deducir las formas de lucha de la clase obrera contradictoriamente con esta concepción, ni tampoco es posible defender la tesis del tránsito pacífico al socialismo y mantener en pie una caracterización del Estado que denuncia su esencia en la violencia de las clases explotadoras sobre las clases explotadas $(\ldots)^{46}$

La vía electoral en Argentina se mostraba incierta ${ }^{47}$. El PSA tenía por tradición priorizar el camino parlamentario del cual el PSAV no se había apartado. Según puede leerse en la cita anterior, la dirección de VC consideraba que existía una mala caracterización del Estado y, por ende, un error en las expectativas. Y continúa señalando que "cuando los revisionistas proclaman las formas de lucha pacíficas como las adecuadas para la toma del poder por el proletariado, están realizando una práctica que coincide con la idea burguesa del Estado". Por el contrario, "el acceso al poder del proletariado no se resuelve a través de la lucha pacífica en la democracia, sino afirmando el poder de la clase obrera con el ejercicio de todas las formas de lucha, que en su desarrollo superior asumen la

\footnotetext{
${ }^{46}$ AAVV, Derrotemos..8

${ }^{47}$ Desde el derrocamiento de J. Domingo Perón en 1955 y hasta 1976 la situación política argentina fue muy inestable, con sucesivos golpes de Estado, gobiernos constitucionales elegidos con proscripción del peronismo y democracias "tuteladas" o vigiladas por las Fueras Armadas.
} 
calidad de lucha armada". ${ }^{48}$ Esta postura (la acérrima defensa de la vía armada y la inevitabilidad de la violencia para la revolución) supuso un primer punto en la confluencia con el maoísmo. VC declaró su adscripción a dicha corriente desde un inicio, a pesar de que luego hubo redefiniciones sobre lo que entendían por tal cosa.

Daniel Aarão, en su investigación sobre las izquierdas brasileras en la década del sesenta $^{49}$, indica que en las organizaciones comunistas convivieron las referencias a múltiples experiencias revolucionarias como un recurso de garantizar legitimidad y autoridad sobre decisiones políticas del ámbito local. Encontramos también en los partidos argentinos referencias variadas, en parte seguramente por la inexistencia de "modelos puros" y también por la necesidad de dar cuenta de la propia realidad. Sin embargo, hay que señalar que la defensa de algún rasgo o elemento de otra experiencia revolucionaria, los llevaba en simultáneo a señalar los límites de la adhesión o, a lo sumo, una fecha o un punto de ruptura de tal apoyo. En el caso de la defensa de la Revolución Rusa, el punto de inflexión estaría dado por la traición del PCUS al marxismo-leninismo a partir del XX Congreso, situación que inscribiéndose en la corriente maoísta pretendían salvar.

Algo similar acontece con el triunfo cubano en 1959. Dada la influencia y el prestigio de la Revolución cubana en el continente, el abordaje era ineludible. Con mucha simpatía frente al proceso, le reconocían ser producto de la búsqueda de caminos alternativos al "reformismo" 50 . Sin embargo, en sus primeros escritos fueron abordando los debates y diferenciándose de dicha corriente. La crítica principal era la de que prescindía del partido y de que escindía al proletariado y las masas del desencadenamiento de la guerra. Finalmente, acusaban al guerrillerismo de ser una concepción pequeño-burguesa de la revolución, sobre todo a partir de las formulaciones de Debray.

Esto nos lleva al siguiente elemento, que es la opción por la conformación de un Partido Político. El armado del Partido supuso no sólo inscribirse en una tradición mundial (el marxismo-leninismo, al que luego se le agregaría el maoísmo), sino dentro del país. VC, proveniente de las filas del socialismo local, atravesó un interesante proceso de identificación y disputa con el PCA. Se produjo una "invención de tradiciones", en el sentido que señala Eric Hobsbawn ${ }^{51}$. La apropiación de ritos, costumbres y símbolos que habrían dejado de pertenecer a quienes las reivindicaban hasta entonces y que ellos se comprometían a defender en este nuevo momento que era exigido.

En el caso de VC, en primer lugar, tuvo que diferenciarse del PS y retomar al PC, por lo que rendían "homenaje a los fundadores de ese partido (...) que difundieron la ideología del leninismo en la clase obrera argentina; que fueron fieles al internacionalismo proletario; que se opusieron a las desviaciones del movimiento comunista internacional; que combatieron el reformismo socialdemócrata $(\ldots)^{52}$. Luego del reconocimiento, inmediatamente "marcar el terreno" de los límites a los que habrían llegado:

\footnotetext{
${ }^{48}$ AAVV, Derrotemos..., 8

${ }^{49}$ Daniel Aarão Reis Filho,. A revolução faltou ao encontro. Os comunistas no Brasil. São Paulo: Brasiliense, 1990, 93-97

${ }^{50}$ Semán, El Partido...

${ }^{51}$ Eric Hobsbawn y Terence Ranger (eds) La invención de la tradición. Barcelona: Crítica, 2002

${ }^{52}$ AAVV, Denunciamos.., 23
} 
El Partido Comunista Argentino, que hace mucho tiempo -más allá de la actual polémica en el movimiento comunista internacional- sigue una línea errónea desvinculada de los intereses de la clase obrera para intentar subordinarlos a los de la burguesía, ha abandonado definitivamente el único instrumento capaz de posibilitar una rectificación. En efecto, la dirección del PCA, al adherir al revisionismo contemporáneo y renunciar a las enseñanzas de la historia del movimiento comunista internacional conducido por Marx, Lenin y Stalin, negados hoy por el revisionismo, renuncia a la herramienta teórica que le permitiría rectificar sus errores para señalar el rumbo a la clase obrera y se integra a una política contrarrevolucionaria a nivel nacional e internacional. (...) $\mathrm{Si}$ el revisionismo en general es la política que favorece al imperialismo en las filas obreras, el caso del Partido Comunista de la Argentina es la más grosera de las caricaturas de la política revisionista. Este Partido divorciado de las masas y de la clase obrera, realizando ingentes esfuerzos para ser aceptado a la cola de la última manifestación de progresismo de la burguesía, que su espejismo le permite vislumbrar, es la manifestación más consecuente del revisionismo y la traición a la clase obrera $^{53}$

Finamente, disputar su lugar y la corriente marxista-leninista:

Para los marxistas leninistas de Argentina queda planteado el deber de contribuir a la lucha internacional del proletariado, derrotando y superando la dirección revisionista del Partido Comunista. Para los marxistas leninistas que todavía pertenecen al Partido de Codovilla, y para los que no pertenecen a él, la misión es derrotar y superar la política del revisionismo. ${ }^{54}$

Entendemos que a través del maoísmo procuraron repensar y reformular la caracterización de la formación económica social del país desde el marxismo (que se había transformado en las décadas anteriores pero que políticamente habían cristalizado más recientemente). Para varias fuerzas políticas de la época, el eje estaba colocado en el elemento de lo nacional, teñido de un radicalismo de izquierda que acompasaba la época; para otros (fundamentalmente las tendencias trotskistas), centrados sólo en el fracaso de la burguesía nacional como clase dirigente, absolutizaban la necesidad de la revolución socialista de inicio; en el caso de los que fueron acercándose al maoísmo, buscaron en el caso chino formas de sintetizar de manera no antagónica (con mayor o menos éxito) los aspectos nacionales y sociales de las revoluciones en los países de América Latina.

La caracterización de la Argentina y el camino para realizar la revolución, sufrieron modificaciones en el caso de VC. Si en discusión con el 'guerrillerismo", en 1964 se enfatizaba el rasgo de "desarrollo capitalista" y "concentración del proletariado "de la Argentina en contraposición con otros países de América Latina, hacia 1966 se enfatizaba

${ }^{53}$ AAVV, Derrotemos..., 4

${ }^{54}$ AAVV, Derrotemos ...,10 
en los rasgos feudales y de atraso, por lo que la revolución se daría en un largo camino que se libraría desde el campo hacia las ciudades. Según la propia dirección, dicha caracterización y consecuente llamamiento político estuvo orientado por una aplicación "dogmática" del maoísmo, sin ver que su verdadero aporte era el del estudio de la realidad nacional a la luz del marxismo-leninismo-maoísmo que les permitiera delinear una estrategia y un programa adecuados.

Hacia 1968 iniciaron un camino de crítica y revisión de dicha formulación, que acompasaba su creciente inserción en el movimiento de masas y las luchas que se intensificaban día a día. Así, caracterizaron desde entonces que Argentina era un país "neocolonial dependiente del imperialismo yanqui" en donde "predominan" relaciones capitalistas y "subsisten" relaciones precapitalistas. Acerca del "neocolonialismo", se limitaron a decir que "es un fenómeno relativamente nuevo (...) que aún no se ha sintetizado teóricamente" 55 . Sin embargo, algunos rasgos son colocados como ejemplo de dicha configuración: por un lado, la "liquidación de la forma de gobierno parlamentaria burguesa y la disolución de los partidos políticos", característica que terminaría de consolidarse en 1966 con el inicio de la autodenominada "Revolución Argentina"; el "control sobre las fuerzas armadas", a partir de su instrucción; la formación de "jerarcas sindicales" adeptos y el avance de la tecnocracia en el plano intelectual-cultural. ${ }^{56}$ Económicamente, el "neocolonialismo" organizaría al país de forma diferenciada, por lo que se generarían "zonas críticas" que políticamente podían ser utilizados como "eslabones débiles". A partir de aquí se introdujeron la teorización sobre la necesidad de cortar la dominación imperialista por esos espacios "menos resistentes", que estaban situados en el interior del país. ${ }^{57}$

Manteniendo que el camino de la revolución era "del campo a la ciudad" a través de una "Guerra Popular Prolongada", sostenían que el frente único estaría motorizado por el proletariado, el campesinado pobre y medio y los intelectuales revolucionarios. De una manera poco precisa, postulaban que como

hoy la revolución tiene centro en las grandes ciudades (...) el problema concreto que tienen hoy los revolucionarios argentinos (...) es cómo crear condiciones para el traslado del centro de la lucha de clases al campo y cómo trasladarlo, elevando esa lucha de clases a la altura del desencadenamiento de la guerra ${ }^{58}$.

Estas formulaciones bastante confusas entre la ciudad y el campo, los "eslabones débiles" y las "zonas críticas", conllevaban además una reformulación del entendimiento de Guerra Popular Prolongada, puesto que se la oponía al "insurreccionalismo" que era caracterizado como los que tienen ilusiones en "una guerra corta" 59 . Es decir, no se contraponía en contenido estratégico, sino en duración.

\footnotetext{
55 "Resolución", Cuadernos Rojos ํ 2 (1970), 32

56 "Resolución", Cuadernos Rojos N² (1970), 25

${ }^{57} \mathrm{VC}$, Resolución..., 46

${ }^{58} \mathrm{VC}$, Resolución..., 43

${ }^{59} \mathrm{VC}$, Resolución..., 41
} 
Los textos existentes sobre VC señalan que para este momento la organización adoptó la vía insurreccional ${ }^{60}$. Sin embargo, en las fuentes consultadas no aparece así. Recién en el II Congreso, en 1976, aparece claramente la formulación, a la par que se abandonaba la caracterización del país como "neocolonial", por el de "capitalista dependiente'. ${ }^{61}$

Con respecto a las teorizaciones acerca del tipo de revolución a ser realizada en Argentina, VC adhirió a la concepción de una "revolución Nacional Democrática y popular hacia el socialismo"62. Es decir, "por etapas" y de manera "ininterrumpida", diferenciándose de "las definiciones del trotskismo y de la OLAS que le otorga carácter socialista"63. Sin embargo, en relación al punto anteriormente tratado, cabe una diferenciación. En todo este período, el contenido de la Revolución de Nueva Democracia y la relación entre las etapas no fue unívoco. Si antes de la conformación del partido, asignaban a que, por el desarrollo capitalista y el peso del proletariado, la primera etapa tenía características socializantes, por el contrario, hacia 1966 el análisis que prácticamente lo asimilaba a una "semi-colonia" los fue llevando a teorizar una "revolución nacional y social", en donde la burguesía nacional era parte "a veces" o "por momentos del frente revolucionario. Esa interpretación fue virando hacia el I Congreso, en donde al calor de los sucesos se volvía a poner el centro en el proletariado y más firmemente con el correr de la década de 1970 se produjo un abandono paulatino de la teoría de que la revolución tendría base en el campo.

Dicho tipo de revolución conllevaba determinar las clases y capas sociales "amigas" y "enemigas'. Pero ni todos los gatos serían pardos, ni podía combatirse contra todos al mismo tiempo. Ello llevaba a precisar, organizar y valorar a las múltiples contradicciones existentes en la sociedad y darse una "táctica" adecuada en cada momento, para avanzar en el objetivo "estratégico".

Uno de los textos que más ha impactado de la obra de Mao-Tse-Tung, fue el de las "Cinco tesis filosóficas" 64 , texto que trascendió a las organizaciones políticas y que fue discutido por intelectuales de diverso signo y filiación política. En particular, las reflexiones contempladas en "Acerca de la contradicción”, invitaban a estudiar y realizar una correcta caracterización de la realidad con el fin de no cometer errores políticos en el accionar sobre ella (lo que se vincula con el otro texto, "Acerca de la práctica"). Si la contradicción era el rasgo distintivo y absoluto de cualquier concreto real, sus distintos aspectos y la lucha entre ellos le asignaba un carácter y movimiento. Y, en relación al estudio de la sociedad y en la voluntad política de su transformación, le cabía a la organización determinar -así como las clases y capas sociales existentes y los vínculos

\footnotetext{
${ }^{60}$ Ver Celentano "Maoísmo..." y "La formación..." 104

${ }^{61}$ AAVV, "Una historia, un compromiso con el marxismo-leninismo" (1999). Temas Revolucionarios, Ediciones PRML, Comisión 50 aniversario VC-PRML - Abril 2015. En este texto, uno de los partidos que reclama ser continuación de VC reconoce que el cambio de conceptualización dela revolución del campo a la ciudad para el insurreccional urbana fue lento.

${ }^{62}$ La formulación la tomamos del I Congreso. A pesar de las diferentes formulaciones o nombres, siempre sostuvieron que la revolución era por fases o etapas.

${ }^{63}$ No Transar [periódico de VC]N 92, 7/9/70. A su vez, se oponían a la OLAS y la Tricontinental "por haber dejado fuera a las organizaciones marxista-leninistas... y por el apoyo a la invasión a Checoslovaquia"

${ }^{64}$ Mao-tse-tung, "Cinco Tesis Filosóficas”, Obras, Tomo III, Bs As: La Paloma, 1974.
} 
entre ellas- cuáles eran las contradicciones que se presentaban y cuál era su carácter (si eran "principales" o "secundarias"). Ese aspecto influyó en las organizaciones maoístas fuertemente, puesto que una de las elaboraciones centrales en los documentos programáticos, era el referido a determinar el tipo de país (es decir, su Formación Económica y Social) y, en relación con ello, delinear una estrategia y una táctica sintetizados en un programa.

Un aspecto no menor que se deriva de formulaciones anteriores o que dialoga con las mismas, es la caracterización del peronismo que hacía VC. El peronismo representaba un desafío en dos sentidos: porque implicaba definir un tratamiento hacia la burguesía nacional en el frente revolucionario (¿dónde ubicarla?) y, segundo, porque presentaba los dilemas sobre la dirección del proletariado.

Recordemos que uno de los puntos de la ruptura en el PSAV habría sido la crisis producida por la "confianza en la potencialidad revolucionaria del peronismo"65. Para comenzar, caracterizaban al peronismo como la expresión política de la burguesía nacional, una clase social cuyo crecimiento ubicaban históricamente en el país al calor de la industrialización sustitutiva de importaciones de los años 20 y 30. Sin embargo, a partir de 1953 habría cambiado de carácter. Esta afirmación deja entrever una de las fuertes discusiones que atraviesan desde mitad del siglo XX a todas las organizaciones de izquierda en Argentina: la caracterización de la burguesía nacional y el tratamiento a darle de cara a la revolución. Sin embargo, la complejidad es mayor si tomamos en cuenta que dicha expresión política era la mayoritaria en el movimiento obrero.

Una de las primeras publicaciones de los creadores de VC tras la ruptura del PSAV caracteriza a la dirección peronista (aquí es interesante notar que no se refiere a todo el movimiento) como "contrarrevolucionario, proburgués y proimperialista" y critica los intento de quienes confiando en que "algún sector interno "cortara las cabezas de los dirigentes vendidos", incurrieron en el "seguidismo" de dicho movimiento" "66. Unos meses más tarde reflexionaban que el error había sido el intento de reconciliar lo irreconciliable y acabaron "reemplazando su vinculación con la clase obrera, por su relación con el peronismo". Realizaron la autocrítica de que creían que podían "revolucionarizar" el movimiento nacional y que ello "sustituía un partido de clase"67. Y que las "manifestaciones de violencia generadas por la clase obrera desde el peronismo" habrían sido exaltada, sin buscar el rol del partido en ella, para elevarlas en la lucha de clases.

A partir de la década de 1960, en cada episodio político de la compleja trama argentina de esos años, denunciaron el carácter "entreguista" de la dirección peronista (y de su expresión sindical), asignándose la tarea de acompañar a los trabajadores en la identificación de la contradicción que suponía esa identidad. La dictadura y la configuración "neocolonial" se habrían dado con el beneplácito y complicidad del peronismo.

\footnotetext{
65 “Adoptamos el nombre de VC", en AAVV, Denunciamos..., 33

${ }^{66}$ Las comillas dentro de la cita figuran en el original, posiblemente refiriendo a otro documento. AAVV, Derrotemos...,4

${ }^{67}$ Semán 53
} 
Por ello, según el texto del Primer Congreso en 1969:

La lucha contra esta influencia ideológica, política y práctica de la burguesía nacional peronista sobre las mayorías obreras, es la terea más importante [destacado da autora] que los comunistas revolucionarios debernos efectuar en la lucha por la elevación de la conciencia política del proletariado al nivel del marxismo-leninismo-pensamiento de MaoTse-Tung. ${ }^{68}$

Reconocen que hay cuestiones "pendientes" vinculadas a la cuestión nacional que son disputadas por la burguesía, caracterizada como una "fuerza dual" en términos políticos y desde la perspectiva revolucionaria. En 1970, en el apartado de balance sobre la historia argentina, le asignan a los gobiernos peronistas el haber "resistido" el neocolonialismo "yanqui", que no habría logrado consolidarse en ese período. El fenómeno respondería no a una posición antimperialista, sino a la necesidad de resguardar los propios intereses sobre el mercado nacional. A partir de 1973, en el marco de los debates electorales y luego con la muerte de Perón, la versión predominante era que era expresión de "la gran burguesía renegociadora", pero que no era lo mismo que el imperialismo. ${ }^{69}$ Evidentemente, estaban adjudicándose esa interpretación en los años previos.

\section{Reflexiones finales}

El triunfo de la revolución en el país más populoso del mundo no pasó inadvertido. Los países socialistas y también los vecinos sintieron tempranamente las repercusiones. Sin embargo, teniendo en cuenta el flujo de la información de la primera mitad del siglo XX y sumando el hecho de que se trataba de un país no occidental y por lo tanto víctima de eurocentrismo, es posible concluir que las noticias eran pocas y, naturalmente, tardías y confusas. La III Internacional y después la URSS tuvieron un rol clave en la difusión de lo que acontecía, entre las fuerzas y partidos de la izquierda. Con el correr de los años la revolución fue ganando la simpatía de otros países del Tercer Mundo y hacia 1960 se conformaron una serie de partidos maoístas. Vanguardia Comunista fue el primero en adoptar esa identidad en Argentina.

El recorrido propuesto y las fuentes trabajadas nos permitieron adentrarnos en el momento constitutivo del partido y en sus primeras elaboraciones y reformulaciones. El eje estuvo colocado en entender cómo y por qué esta organización creía que el maoísmo (o sus herramientas conceptuales) serviría para orientar su práctica revolucionaria. A su vez, ponía en diálogo la experiencia propiamente china con formulaciones que le podían ayudar a comprender e intervenir mejor en Argentina. Entendemos que tanto las afirmaciones como los replanteos expresaron ese camino (ni unívoco ni lineal) de "integración” del marxismoleninismo-maoísmo a la realidad de dicho país. Llegando finalmente a la formulación de una revolución por el camino insurreccional desde las ciudades, por etapas, pero con

\footnotetext{
${ }^{68}$ Vanguardia Comunista, Proyecto de Resolución..., 8

${ }^{69}$ No Transar [periódico de VC] N $125,23 / 8 / 73$
} 
hegemonía proletaria en un país capitalista dependiente como consideraban que era la Argentina. Y VC se proponía ser la vanguardia de dicho proceso, ya que el PC habría abandonado y traicionado la histórica lucha y el peronismo mayoritario entre los obreros expresaría los intereses de la burguesía.

Cómo hacer la revolución en Argentina y cómo salir del "gorilismo" sin caer en el "seguidismo", fueron las preocupaciones que tempranamente motivaron a esta naciente organización a buscar nuevas herramientas político teóricas en un mundo conmovido desde sus cimientos. Según Cristina Tortti, el conjunto de organizaciones que se enmarcarían dentro de la denominada "Nueva Izquierda", se habrían caracterizado por el intento de integrar "peronismo", "socialismo" y "revolución". ${ }^{70}$ No sin vaivenes, entendemos que en las primeras elaboraciones de $\mathrm{VC}$ es posible verificar esa preocupación. En este caso en particular, la especificidad o aporte de las organizaciones maoístas, de la cual VC es parte fundamental, estuvo dado por la incorporación de herramientas teórico-políticas provenientes de la experiencia china y del "pensamiento Mao-Tse-Tung" con las cuales reformularon los análisis de la sociedad y la revolución en Argentina. En particular y de manera singular, entendieron a la revolución y el socialismo como el objetivo estratégico (cada una en la etapa correspondiente, pero íntimamente vinculadas) y ubicaron al peronismo como una problemática clave de la táctica para alcanzarlo.

Queda por delante un trabajo de profundización del espectro del maoismo dentro del campo político argentino y sus vínculos con otras corrientes, así como un trabajo que aborde al maoísmo en América Latina.

\section{Bibliografía}

Aarão Reis Filho, Daniel. A revolução faltou ao encontro. Os comunistas no Brasil. São Paulo: Brasiliense, 1990

Alexander, Robert. International Maoism in the Developing World. London: Paeger, 1999

Celentano, Adrián. "La formación de Vanguardia Comunista, de la crisis del socialismo a la adopción del maoísmo y el problema de la construcción del partido revolucionario entre 1965 y 1969," Ponencia presentada en las VII Jornadas de Historia Política. Tandil, 6 y 7 de setiembre de 2012

Connelly Marisela, "Influencia del Pensamiento de Mao en América Latina". En: Estudios de Asia y África XVIII: 2, 1983. 215-231

Duval Natalia, Los sindicatos clasistas SITRAC (1970-1971), Buenos Aires: CEAL, 1988

Flores, Gregorio, Sitrac-Sitram, del Cordobazo al Clasismo. Buenos Aires: Magenta, 1994

Gordillo, Mónica. Córdoba en los 60: la experiencia del sindicalismo combativo. Córdoba: Colección de Manuales de Cátedra, 1996.

Hobsbawn Eric e Ranger Terence (eds) La invención de la tradición. Barcelona:Crítica, 2002

Mao-tse-tung, "Cinco Tesis Filosóficas", Obras, Tomo III, Bs As: La Paloma, 1974

Rothwell, Mtathew. Transpacific Revolutionaries: The Chinese Revolution in Latin America. New York: Routledge, 2013.

\footnotetext{
${ }^{70}$ Tortti, La Nueva Izquierda...
} 
Rupar, Brenda. A emergência do maoísmo na Argentina: uma aproximação através de Vanguardia Comunista e o Partido Comunista Revolucionario. Dissertação de Mestrado. Niterói: UFF, 2016.

Tortti, M Cristina, "La nueva izquierda a principios de los '60. Socialistas y comunistas en la Revista 'Che",, Revista Estudios Sociales No 22/23, Santa Fe: Universidad Nacional del Litoral, 2002

Tortti, María Cristina (org) La Nueva Izquierda Argentina (1955-1976). Socialismo, peronismo y revolución. Rosario: Prohistoria, 2015

Tortti, María Cristina, El "viejo" partido socialista y los orígenes de la "nueva" izquierda. Buenos Aires: Prometeo, 2009

\section{Fuentes Primarias}

Documentos partidarios [consideraremos tanto los de $\mathrm{VC}$ como los escritos de balance posteriores, publicados por protagonistas pertenecientes ya a otras organizaciones]

AAVV, Derrotemos al Revisionismo, Bs As: Ed. No Transar, 1964. Usamos versión publicada por el PRML, a 50 años de la fundación de VC. Buenos Aires, 2015.

AAVV, Partido Vanguardia Comunista, Denunciamos el falso comunismo de Codovilla, Bs As: Ed. No Transar, 1965

AAVV, "Una historia, un compromiso con el marxismo-leninismo" (1999). Temas Revolucionarios, Ediciones PRML, Comisión 50 aniversario VC-PRML - Abril 2015

Ortiz, Sergio, Vidas y Luchas de Vanguardia Comunista, Tomo II, Buenos Aires: Nuevos Tiempos, 2010.

Ortiz, Sergio. Partido de la Liberación, Breve historia del Partido de la Liberación, documento aprobado por el Comité Central del Partido de la Liberación en su XVII reunión plenaria, 8 y 9 de julio de 1995

Semán, Elías, El Partido Marxista Leninista y el guerrillerismo, Ed No Transar, 1964. Usamos versión editada por El Topo Blindado, Buenos Aires, 2013

Soto, Américo, Vidas y Luchas de Vanguardia Comunista, Tomo I, Buenos Aires: Nuevos Tiempos, 2004

Vanguardia Comunista, Proyecto de Resolución sobre construcción del Partido. Vanguardia Comunista en marcha hacia la constitución del Partido Comunista Revolucionario, 1969

Periódicos: No Transar [periódico de VC]. 1966-1973

Revistas: Cuadernos Rojos [CC de Vanguardia Comunista]. 1970 